\section{Denise Martin'}

José Quirino"I

Jair Mari"

\section{Depression among women living in the outskirts of São Paulo, Southeastern Brazil}

Programa de Mestrado em Saúde Coletiva. Universidade Católica de Santos. Santos, SP, Brasil

" Departamento de Psiquiatria. Universidade Federal de São Paulo. São Paulo, SP, Brasil

\author{
Correspondence: \\ Denise Martin \\ Universidade Católica de Santos \\ Coordenadoria de Pós-graduação e Pesquisa \\ Programa de Mestrado em Saúde Coletiva \\ R. Carvalho de Mendonça, 144 \\ 11070-906 Santos, SP, Brasil \\ E-mail: demartin@terra.com.br
}

\begin{abstract}
OBJECTIVE: To assess the meaning of depression in women diagnosed with the disorder, and the context of care given by the psychiatrists who follow them up.

METHODS: Qualitative study performed in Embu, outskirt of São Paulo, between August 2002 and January 2003. Etnographic observation and indepth interview were carried out with 16 women diagnosed with depression in primary care, and four psychiatrists. After exhaustive reading, data were grouped into categories and assessed. The assessment of outcomes was based on the concept of culture.
\end{abstract}

RESULTS: Women interviewed are well aware of the disorder, and accept treatment based on medication. For psychiatrists, depression is a term understood by the common sense. All women interviewed identified the onset of the disease from a past event such as: death of a son, violent episodes connected with drug traffic, unemployment, and partners' aggressiveness. Violence was common in the every day life of the interviewed women both inside and outside their homes.

CONCLUSIONS: For these women, depression is a way to express their feelings, such as unhappiness in a context of poverty and violence. Psychiatrists go beyond their clinical functions and play an important role on reorganizing the daily life of these women.

KEY WORDS: Depression. Health knowledge, attitudes, practice. Qualitative research. Mental health. Social anthropology. Women.

\section{INTRODUCTION}

Depression is a severe public health problem, confirmed by the importance of mental disorders compared to other diseases. This disorder involves daily life of people and their social relationship, whether it is in the family, work or community.

It is estimated that by 2020, depression will be the second leading disabling disease in the world. ${ }^{16}$ International ${ }^{5}$ and national ${ }^{2,3}$ studies show that depression and anxiety symptoms are more prevalent among women. Women, and people with low education and economically impaired have greater risk of presenting depression. ${ }^{19,20}$

One way to understand this greater female vulnerability to depression is to approach the issue from a cultural perspective. Several authors have reported how depression can be understood with reference to the cultural segment in which people are. ${ }^{7,13,14,23}$ 
Culture not only gives different emphasis to certain emotions, but may also give specific attributions to the intensity of experiences and expression. ${ }^{13}$ Manson ${ }^{13}$ states that the best understanding of depression will take into account much more than the symptoms expressed by the patients. The social contexts and the cultural forces shaping the everyday life must be taken into account because they give meaning to the interpersonal relations and events in life.

Thus, understanding this disease also encompasses its sociocultural context. According to Fabrega ${ }^{7}$, there are two aspects interconnected with depression: on one side neurochemical and neuropsychological changes that in their total highlight behavioral changes, which may show specificity measure through time and space. On the other side, generic and abstract shapes or frames that dim the way these behavioral changes are expressed in a culturally contextualized way. This author also shows the necessary dialog between the biological conditions, and the cultural context in which they are expressed.

Other examples are the clinical studies on depression performed in non-Western cultures, mentioned by Marsella et al. ${ }^{14}$ They highlighted the reduced frequency or absence of the psychological components in depression and the predominance of somatic aspects especially for feelings of guilty, despair, self-destruction, and suicidal ideation.

There is wide bibliography on the issue, with clinical studies, diagnosis, and symptomatology that have been developed for at least three decades. However, most theories on depression ignore the importance of cultural factors. ${ }^{14}$

The objective of the present study was to assess the meaning of depression for women diagnosed with the disturbance and the context of care given by psychiatrists who follow them up.

\section{METHODS}

The town of Embu is located $27 \mathrm{~km}$ away from the center of the capital of São Paulo, and is part of its metropolitan region. It is considered a tourist place characterized by the trade of handcraft and it is also called "Embu das Artes". Apart from the commercial center, the districts are very poor. In 2004, the population was 232, 165 inhabitants. Most houses of the town are small, built by the owners themselves in concrete, with a high number of illegal occupations and shanty towns. In 2003, the homicide rate was 71/100.000 inhabitants, twice as great as the State of São Paulo (36/100.000).*
The main characteristic of Embu is poverty, together with the lack of infrastructure in health, education, housing, and leisure. Care in mental health in the town is characterized by poor human resources.

A qualitative study was performed, including dense ethnographic observation and in-depth semi structured interviews. ${ }^{17,21}$ Sixteen interviews were carried out with women diagnosed with depression (F32 and F33 - CID $10^{18}$ ) seen in the basic health department (UBS) in Embu, and four interviews with psychiatrists of the town health department.

Follow-up ethnography was restricted to the neighboring areas of the health care facility, with the constant and threatening presence of drug dealers nearby.

Data collection was performed between August 2002 and January 2003. The following inclusion criteria for women were adopted: they had to live in the place, be referred by a psychiatrist, have diagnosed depression and undergo treatment, and they had to use prescribed antidepressive medication.

The four interviewed psychiatrists (three men and one woman) worked in the town at the time. Two worked in health care units, one worked in the Center for Psychosocial Attention and the other worked in the ER and outpatient ward. Interviews were performed in the workplace of psychiatrists. The interview guidelines dealt with the care in mental health and depression, in their particular ways, understanding the way of life of women diagnosed with depression, diagnosed criteria used and professional background (intern, post graduate students).

We have opted to conduct the interviews with women in a certain health care unit because it is located in one of the poorest region of town, offering an exclusively outpatient care in psychiatry.

One of the psychiatrists from the health care unit indicated the women with diagnoses of depression to be interviewed according to established criteria. Interviews (recorded and transcribed) lasted from 40 minutes to two hours, and were conducted in a separate office at the health care unit. Interviews had questions on how and why patients sought medical care, their reasons and complaints, their understanding of the disorder, their reasons for the explaining of the disorder, stated relationship with family and community after diagnoses, life condition and sociability in Embu, and sociodemographic data. Statements of the participants were identified by letters standing for fictional names and the psychiatrists identified by numbers (psychiatrist 1 to 4$)$.

* Fundação SEADE. Perfil Municipal - Estado de São Paulo [maps on the Internet]. São Paulo; 2005. Available at: www.seade.gov.br/produtos/ perfil/index.php [Accessed on 11/18/2006) 
Interviews were conducted until full exploration of the guidelines. After exhaustive reading of the transcriptions, data were grouped into categories and assessed according to the objectives of the study. Outcomes were interpreted based on the concept of culture. ${ }^{12,17}$ Qualitative component of the anthropologic research was essentially to employ acts, facts, speeches and interpretations to form a logical model that explained this reality, which was not accessible to individuals in most cases. ${ }^{15}$

The study was approved by the Committee for Ethics on Research of the Universidade Federal de São Paulo.

\section{RESULTS AND DISCUSSION}

The age of the interviewees ranged from 20 to 57 years old, all of them having children, babies and adults. Formal education was poor, only two women had finished high school. Most of them (12) had incomplete elementary school, three had finished high school and one was illiterate. Eleven interviewees came from other states (usually the poorer ones). Four interviewees were born in São Paulo, and another one was born in Portugal coming to Brazil still a baby.

\section{Context of psychiatric care and treatment}

Care in mental health has been barely happening, inside a precarious and limited context, either because of the scarcity of psychiatrists or because of a high demand. For the interviewed psychiatrists, the population that used health services assimilated the term depression, which is now part of the common sense as illustrated by the following statement:

"... depression is a word that is used for everything, for example: the alcoholic, he is depressed, the psychotic, he is depressed, the schizophrenic is depressed. Everything is depression, then the person comes and says: my problem is depression ...depression is a word that got into the popular concept, accepted and respected by people, and that is it, everything is depression now." (psychiatrist 1)

Both the diagnoses of professional and the understanding by patients presented problems in defining the disturbance. As it is a term incorporated by the common sense, it got far from the medical definition and was used by the population inaccurately. This appropriation, together with diagnoses and medication given by other professionals, also made it difficult to classify symptoms. Some patients would arrive in the psychiatrists already with diagnoses of depression given by other services or doctor (ER, cardiologist or gynecologist). Making the term trivial may lead to unsuitable or late diagnoses.

Professionals interviewed mentioned the continuous use of medication (such as fluoxetine and some benzodiazepines). In some cases, interviewed people got to medical care with a long history of use of these medications, and it was difficult for the doctor to question suspending prescription. In other cases, professionals highlighted that the population many times could not recognize the symptoms as a disease and much less as a problem that required medical help. Several cases were diagnosed after suicidal attempt.

Symptoms described by patients in interviews went beyond clinical criteria defined by ICD-10. ${ }^{18}$ Theoretical understanding of depression may acquire several meanings, either by the way it is defined by psychiatric manuals, by general practitioners who take care and diagnose the disorder in the population, or by the people who suffer from the disorder, and even by the social relations of the patients. ${ }^{11}$

For the women interviewed, diagnose and treatment were mainly focused on the doctor, (psychiatrist in this case). When they were asked about alternative treatment, most of them did not even think about this possibility. Some of them mentioned the help of psychologists, religious people or soothing teas and herbs. Although most declared that they followed one or more religions, the focus of the treatment was the physicians. For some, God's help was represented by the psychiatrist being in their lives.

All interviewed women used antidepressive and sedatives. Treatment was based on medication and was assessed positively among women, as shown by the following statement:

"Yeah, and then I was referred to him, and he said: that he hoped I would not be back again but that this could happen every now and then because I've already had it, and I, it's been not even 15 days that I'm taking the medication and I already felt some improvement".(R.)

Medication has a positive connotation, as a central base on the recovery process. As Silveira ${ }^{25}$ states, in medical appointment it is possible to make the complaints, make suffering socially legitimate, and solve the problem pragmatically with medication. Accepting psychiatric treatment is justified and the need for overcoming the biomedical aspects of depression is revealed.

Diagnoses, notion of disease and their causes for women

All women interviewed accepted the diagnoses of depression, made by the psychiatrists or by other health professionals. Interviewed patients did not have a clear notion of the disorder, as illustrated by the following statements:

"No, I've heard that those who have depression if they do not take care, they may end up crazy, or may have a heart arrest, or also a stroke, I've heard, I saw it myself, I'm not sure".(M.) 
"Gee, I don't know, because, sometimes, I get scared, because, sometimes, people say there is a cure and others say there is no cure and then I ask, o God, is there a cure for it? (E.)

Additionally to the association of madness, understood here as losing one's mind, there is association with other diseases. The development of the disorder is little known and the notion of cure is vague or even unknown.

Despite the inaccuracy, the interviewed women accepted the medical diagnoses. It all goes as if the psychiatrist named the suffering and in a way, made it legitimate. The medical authority was enough for a patient to believe in possible improvement and continued the treatment with medications. Medical intervention occurs in a broader context, marked by economical and power relations. ${ }^{10,25}$ The doctor has knowledge that is unknown to the patient but that is socially legitimized, even in poor context such as that from Embu. ${ }^{22}$

Different from the poor definition of the disorder, the interviewed women had several explanations for their causes. The source of depression was related to events in their lives, most of them external. The causes of the disorder were external, closely related to the context they lived in the outskirt of town, such as unemployment, financial problems, victimization, or witnessing murderers, relatives being arrested, presence of drug dealers and drug users in the neighborhood. Other causes were private: death of relatives, aggressions, betrayal, and partner's alcoholism.

The following statements illustrate this diversity of explanations for the cause of depression:

"I believe it is the worry, the financial life, it shakes you a lot, you see? Because, sometimes, you want to buy things, you are used to buying things and you know you cannot, having children, seeing your husband nervous because he does not have a job, you see? So I believe this is what causes depression, too much sorrow someone who loses a very close person..." (G.)

"Lack of transport, of jobs and also the drugs, crookedness that is very frequent here, extremely frequent as the doctor said, it has been proved that here is the place with most outlaws in the whole world, this makes us very scared, I believe that is why our heads go bad, almost all mothers nowadays have depression, or one or other problem”. (M.)

According to the interviewed women, depression may have several causes, from poverty to issue involving gender and religiosity. The term depression encompassed perfectly the several events described in the lives of these women and in a way shaped the suffering they experienced.
In the description of their daily life, ceaseless aggressiveness were clear, together with adverse social relations, attributing causality to drug trafficking, and the poorly accepted inferiority in the gender relationships. These explanations, supported by external causes, exempted women from the responsibility of the disease. They were not guilty for their suffering, but victims of a violent and unequal society.

\section{Violent daily life and gender relations}

Even (involuntarily) restricted, the ethnographic observation and interviews revealed that there were few places for the population to perform leisure activities. Distance from the downtown and difficulty in transportation contributed to restrict sociability of these women to their homes. Many women mentioned as their only leisure to visit relatives. Some of them attended church, read the Bible, visited the handcraft fair in Embu or went to malls.

In the region, with no urban plan, the activities were centered in the neighborhood. However, friendship with neighbors was poor, with few support and bonds.

A strong fact in the region, described by all interviews, was the frequent contact with drug peddling and consequently, with the violence connected with this activity. All the interviewed women talked about the fear of their children getting involved with it, some of them were already involved, of the dangers of being in the streets until late at night and of the fear of neighbors in general, that may be outlaws. The way to defend ones' self was to be isolated at home. There was in this context, a local ethics marked by fear and respect for outlaws. They avoided talking and searching for the responsible. The police was not seen as an authority. The statements exemplify living with constant violence and delinquency:

"Mrs. M., you are not stupid at all, he said. 'What is it Marcos, what is going on' I told him...-'So, you are going to tell me you do not know that your son is seeing my wife?'I replied: 'No, he told me he never had anything to do with her'. And then he told me... - 'There is a problem Mrs. M I am going to kill your son...' and after everything happened, after my son had died, that my eldest son and my daughter in law came to me and told me my son was involved with drugs and was having an affair with Marcos'wife..."(M.)

"Ah, no, out there is very dangerous, of course, not for me, I am always inside my home, so there is nothing to happen to me, but there are many bad people who use drugs, near my house, as it faces the street, there is lot of noise all night long." (E.)

In this context, the poorness of sociability of these women is evident; they are always protecting themselves 
against the everyday violence. Fear is always present, whether it is of having relatives involved with the crime, or with the possibility of being involved with it.

Another aspect to be highlighted is the inequality of the gender relations. Interviews showed that relationships with partner were marked by submission. In some cases, these women depended financially on their partners, in other cases they were employed, in poor, low paid jobs. For many women in Brazil, the need for their presence in the job market follows the deepening of poverty and the "double shift". They have responsibilities not only in the house but also in the financial area they experience an update of gender inequalities. ${ }^{4}$

Women were also responsible for children's education. Interviewed women complained about alcoholic husbands and of having to do everything alone - take care of home, children and work - and about the aggressiveness of the partners against them or the children, and the lack of dialog. This domestic violence, extensively mentioned in the bibliography, ${ }^{9}$ must be understood as a result of power relations between men and women. The inequality between them is visible, where men determine women's role, however, this is a social rather than biological determination. ${ }^{24}$

Some studies associate domestic violence with mental disorders and depression, revealing its importance for mental health in women. ${ }^{1,5,8}$

In Embu, women also accepted the partners they had:

"Well, he was never a good father.. he was never the good father that my children needed, I wouldn't mind being beaten every day, if when he arrived home he gave some affection to the children... I had to feed my children before he got home... when he arrived I had to take the children away not to be near him... He was aggressive and betrayed me..."(G.)

"When he drinks a lot he does get aggressive, he wants to beat me, anything I say, if I say I'm upset, sometimes I get nervous, if I say I'm upset, he comes to me and wants to beat me, I tell him not to beat me anymore for Christ sake because he has already beaten me a lot, even when I was pregnant of this son who is know 18 , he beat me. (M.)

Relations of genders lived by these women reveal that, in many cases, aggressiveness occurred not only outside the house. If the daily life on the streets was marked by direct contact with delinquency, inside their houses, these women also faced situations of extreme dependency and fragility.

The context of life was marked also by the absence of happiness and pleasure in living. Interviews indicated that depression is also a language to express unhappiness, in a tense context of poverty and fear.

\section{FINAL CONSIDERATIONS}

The present study showed how the disorder, although it is focused on a psychiatric treatment and in medications, has a specific sociocultural context, with its reasons and justifications.

The term depression, according to psychiatrists, was incorporated by the common sense. The use of the term was inaccurate and inadequate for the population seen in mental health, demonstrating an idea of disease used by the local population. According to the interviews, its diffusion was justified because of the context of hard life they lived in.

Difficulty in diagnosing the disorder in this sociocultural context of exclusion and violence was in contrast with the passive acceptance of diagnoses and treatment. Once identified with depression, women accepted diagnoses and the way offered by physician as a treatment: medication. The disorder was little understood by the interviewees however, for them it was not important. What was important is that their suffering, whose cause was the aggressive and unequal daily life, had now a name - depression - and even a medication. Cure was obscure, but receiving treatment helped them dealing with the suffering.

Thus, the focus of suffering moved from the undesirable life to a disease explained by the psychiatrist, from living with it with medication. Medication was a way to give objectivity to the suffering of these women. However, when they spoke about the experience of the disease, the objectivity of the treatment reminded a kaleidoscope of explanations that tried in some way to justify, without changing, the daily suffering.

The health professional referred the patients' complaints to biomedicine. Women with depression diagnoses expressed their suffering in the social, cultural and personal context in which they lived. Therefore, the term depression refers to distinct cultural universes, that of psychiatrists and that of patients.

The idea of depression, incorporated in the common sense, revealed the plasticity with which the term is used. It goes beyond the pathologic notion defined by biomedicine and enables encompassing all negativity of daily life. In the cases of the interviewees, negativity was expressed in the contact with delinquency and drug peddling, with domestic aggressiveness and with unequal gender relations. Improvement of this daily life is far. In face of such powerlessness, daily suffering was hidden by a socially acceptable professional (the psychiatrist) making the suffering legitimate.

A possible explanation of this context is in admitting depression as a physical-moral disturbance rather than a disorder, as Duarte ${ }^{6}$ suggests. Just as the "nervous", depression would be a catalyze with which women 
expressed their physical and moral disturbances. That is, "the life conditions, situations, or events considered irregular or abnormal by the social subjects and that involve or affect not only their immediate corporality but also their moral life, their feelings and their selfrepresentation". ${ }^{6}$

As psychiatrists state, depression is an accepted mental disorder. If it is considered as a physical-moral disturbance, it is possible for the depressed people to justify all the suffering experienced, giving new meanings to their experience marked by suffering. In the present study, depression expressed social drama.
Psychiatrists interviewed surpassed their clinical functions and had a role in reorganizing the daily life of these women, and to a certain extent, to deal with their powerlessness to change the context they live in. This analysis, focused on the interlocution between anthropology and psychiatry, intends to contribute to interventions culturally more suitable to the context in which this population lives. To think about depression as a physical-moral disturbance may enable a more realistic idea of the daily life of these women and the solutions for their suffering. 


\section{REFERENCES}

1 Adeodato VG, Carvalho RR, Siqueira VR, Souza FGM. Qualidade de vida e depressão em mulheres vitimas de seus parceiros. Rev Saude Publica. 2005;39(1):10813.

2. Almeida-Filho N, Lessa I, Magalhães L, Araújo MJ, Aquino E, James SA, et al. Social inequality and depressive disorders in Bahia, Brazil: interactions of gender, ethnicity, and social class. Soc Sci Med. 2004;59(7):1339-53.

3. Andrade LHSG, Viana MC, Silveira CM. Epidemiologia dos transtornos psiquiátricos na mulher. Rev Psiquiatr Clin. 2006;33(2):43-54.

4. Dantas-Berger SM, Giffin K. A violência nas relações de conjugalidade: invisibilidade e banalização da violência sexual? Cad Saude Publica. 2005; $21(2): 417-$ 25.

5. Desjarlais R, Eisenberg L, Good B, Kleinman A. World Mental Health. Problems and Priorities in Low-Income Countries. Oxford: Oxford University Press; 1995.

6. Duarte LFD. Indivíduo e pessoa na experiência da saúde e da doença. Cienc Saude Coletiva. 2003;8(1):173-84.

7. Fabrega Jr H. Problems implicit in the cultural and social study of depression. Psychosom Med.1974;36(5):377-97.

8. Fischbach RL, Herbert B. Domestic violence and mental health: correlates and conundrums within and across cultures. Soc Sci Med. 1997;45(8):1161-76.

9. Giffin K. Violência de Gênero, sexualidade e saúde. Cad Saude Publica. 1994;10(Supl 1):146-55.

10. Kirmayer LJ. Cultural Variations in the response to psychiatric disorders and emotional distress. Soc Sci Med. 1989;29(3):327-39.

11. Kleinman A. Patients and healers in the context of culture. Berkeley: University of California Press; 1980.

12. Lévi-Strauss C. Antropologia Estrutural. Rio de Janeiro: Tempo Brasileiro; 1970.

13. Manson SM. Culture and major depression. Current challenges in the diagnosis of mood disorders. Psychiatr Clin North Am. 1995;18(3):487-501.
14. Marsella AJ, Sartorius N, Jablensky A, Fenton FR. Crosscultural studies of depressive disorders: an overview. In: Kleinman A, Good B, editores. Culture and depression. Studies in the Anthropology and CrossCultural Psychiatry of Affect and Disorder. Berkeley: University of California Press; 1985. p.299-324.

15. Martin D, Andreoli SB, Quirino J, Nakamura E. Noção de significado nas pesquisas qualitativas em saúde: a contribuição da antropologia. Rev Saude Publica. 2006;40(1):178-9.

16. Muray CJ, Lopez AD. Global mortality, disability, and the contribution of risk factors: Global Burden of Disease Study. Lancet. 1997;349(9063):1436-42.

17. Oliveira RCO. O trabalho do antropólogo: olhar, ouvir, escrever. Rev antropol. 1996;39(1):13-37.

18. Organização Mundial da Saúde. Classificação de transtornos mentais e de comportamento da CID10: referência rápida. Trad. de G Baldisserotto. Porto Alegre: Artes Médicas; 1997.

19. Patel V, Araya R, Lima M, Ludermir A, Todd C. Women, poverty and common mental disorders in four restructuring societies. Soc Sci Med. 1999;49(11):1461-71.

20. Patel V. Cultural factors and international epidemiology. Br Med Bull. 2001;(57):33-45.

21. Patton MQ. Qualitative evaluation and research methods. Newbury Park: Sage; 1990.

22. Quirino JS, Miranda C, Leite AS, Pereira, MFA. Perturbações da normalidade sócio-cultural. São Paulo Perspec. 1992; 6(4):85-91.

23. Rodrigues N, Caroso CA. Idéia de "sofrimento" e representação cultural da doença na construção da pessoa. In: Duarte LFD, Leal OF, organizadores. Doença, sofrimento, perturbação: perspectivas etnográficas. Rio de Janeiro: Fiocruz; 1998. p.137-50.

24. Silva IV. Violência contra mulheres: a experiência de usuárias de um serviço de urgência e emergência de Salvador, Bahia, Brasil. Cad Saude Publica. 2003; 19 (Supl 2): S263-72.

25. Silveira ML. O nervo cala, o nervo fala: a linguagem da doença. Rio de Janeiro: Fiocruz; 2000. 